„This is the peer reviewed version of the following article: Sebastian Henning, Hiroshi Ishikawa, Laura Kühn, Juan Herranz, Elisabeth Müller, Alexander Eychmüller and Thomas J. Schmidt (2017).

Unsupported Pt-Ni Aerogels with Enhanced High Current Performance and Durability in Fuel Cell Cathodes. Angewandte Chemie Int. Edition, 2017, Volume 56 (36), page 10707-10710, which has been published in final form at DOI:10.1002/anie.201704253.

This article may be used for non-commercial purposes in accordance with Wiley Terms and Conditions for Self-Archiving."

\title{
Angewandte Chemie Unsupported Pt-Ni Aerogels with Enhanced High Current Performance and Durability in Fuel Cell Cathodes
}

\author{
--Manuscript Draft--
}

\begin{tabular}{l|l} 
Abstract: & $\begin{array}{l}\text { Highly active and durable oxygen reduction catalysts are needed to reduce the costs } \\
\text { and enhance the service life of polymer electrolyte fuel cells }(\mathrm{PEFC}) . \text { This can be } \\
\text { accomplished by alloying Pt with a transition metal (e.g. Ni) and by eliminating the } \\
\text { corrodible, carbon based catalyst support - however, materials combining both } \\
\text { approaches have seldom been implemented in PEFC cathodes. In this work, an } \\
\text { unsupported Pt-Ni alloy nanochain ensemble (aerogel) demonstrates high current } \\
\text { PEFC performance commensurate with that of a carbon supported benchmark (Pt/C) } \\
\text { following optimization of the aerogel's catalyst layer }(\mathrm{CL}) \text { structure. The latter is } \\
\text { accomplished using a soluble filler to shift the CL's pore size distribution towards larger } \\
\text { pores which improves reactant and product transport. Chiefly, the optimized PEFC } \\
\text { aerogel cathodes display } \approx 2.5 \text {-fold larger surface-specific ORR activity than Pt/C and } \\
\text { maintain } 90 \% \text { of the initial activity after an accelerated stress test }(v s .40 \% \text { for Pt/C). }\end{array}$
\end{tabular}




\title{
Unsupported Pt-Ni Aerogels with Enhanced High Current Performance and Durability in Fuel Cell Cathodes
}

\author{
Sebastian Henning ${ }^{[a]}$, Hiroshi Ishikawa ${ }^{[b]}$, Laura Kühn ${ }^{[c]}$, Juan Herranz ${ }^{[a] *}$, Elisabeth Müller ${ }^{[d]}$, \\ Alexander Eychmüller ${ }^{[c]}$ and Thomas J. Schmidt ${ }^{[a, e]}$
}

Abstract: Highly active and durable oxygen reduction catalysts are needed to reduce the costs and enhance the service life of polymer electrolyte fuel cells (PEFCs). This can be accomplished by alloying

Pt with a transition metal (e.g. Ni) and by eliminating the corrodible, carbon-based catalyst support - however, materials combining both approaches have seldom been implemented in PEFC cathodes. In

this work, an unsupported Pt-Ni alloy nanochain ensemble (aerogel) demonstrates high current PEFC performance commensurate with

that of a carbon-supported benchmark (Pt/C) following optimization

of the aerogel's catalyst layer $(\mathrm{CL})$ structure. The latter is accomplished using a soluble filler to shift the CL's pore size distribution towards larger pores which improves reactant and product transport. Chiefly, the optimized PEFC aerogel cathodes display $\approx 2.5$-fold larger surface-specific ORR activity than $\mathrm{Pt} / \mathrm{C}$ and maintain $90 \%$ of the initial activity after an accelerated stress test (vs. $40 \%$ for $\mathrm{Pt} / \mathrm{C})$.

Polymer electrolyte fuel cells (PEFCs) are a promising, environmentally friendly alternative to combustion engines for automotive application, yet further cost reductions and durability improvements are necessary to foster their widespread use. ${ }^{[1]}$ To reach cost targets, the amount of $\mathrm{Pt}$ required for catalyzing the reactions inside the PEFC needs to be reduced $\approx 4$-fold, down to $0.1 \mathrm{~g}_{\mathrm{P}} / \mathrm{kW} .^{[1]}$ Thereby, efforts focus on the catalytically more

\footnotetext{
[a] Electrochemistry Laboratory, Paul Scherrer Institut, 5232 Villigen, Switzerland

[b] Interdisciplinary Graduate School of Medicine and Engineering,

[c] University of Yamanashi, 4 Takeda, Kofu, 400-8511, Japan

c] Physical Chemistry, Technische Universität Dresden, Bergstr. 66b, 01062 Dresden, Germany

[d] Laboratory of Biomolecular Research, Paul Scherrer Institut, 5232 Villigen, Switzerland

[e] Laboratory of Physical Chemistry, ETH Zurich, 8093 Zurich Switzerland

* Corresponding author; E-mail: juan.herranz@psi.ch
}

demanding oxygen reduction reaction (ORR), for which improved activity is commonly achieved by alloying Pt with nonnoble metals. ${ }^{[2]}$ Complementarily, the excessive loss of performance observed during PEFC operation is caused by the corrosion of the carbon support used in state-of-the-art platinum catalysts $(\mathrm{Pt} / \mathrm{C})$ upon high potential excursions, ${ }^{[3]}$ and has intensified research on non C-supported and unsupported catalysts over the last years. ${ }^{[4]}$ Aiming to tackle both challenges, our previous work on an unsupported $\mathrm{Pt}_{3} \mathrm{Ni}$ aerogel (cf. transmission electron microscopy (TEM) images in Supporting Information (SI) in Figure $\mathrm{SI}-1$ ) showed that this material reaches the ORR activity target for automotive PEFCs set by the U.S. Department of Energy (DOE; i.e. $440 \mathrm{~A} / \mathrm{g}_{\mathrm{Pt}}$ at $0.9 \mathrm{~V}$ vs. the reversible hydrogen electrode $\left.\left(\mathrm{V}_{\mathrm{RHE}}\right)\right)$ when tested in liquid electrolyte half cells using the rotating disk electrode (RDE) technique. ${ }^{[5]}$ Considering the need to translate these advances to the technical system and the lack of fuel cell studies dealing with unsupported systems, ${ }^{[6]}$ this study reports on the successful optimization of the $\mathrm{Pt}_{3} \mathrm{Ni}$ aerogel PEFC performance, also demonstrating the material's remarkable stability under accelerated stress test (AST) conditions.

The first PEFC tests in $\mathrm{H}_{2} /$ air conditions revealed poor performance of $\mathrm{Pt}_{3} \mathrm{Ni}$ vs. $\mathrm{Pt} / \mathrm{C}$ cathodes (Figure $1 \mathrm{~A}$ ) which is attributed to inefficient gas transport, discernible from the large mass transfer losses that arise when switching from $\mathrm{O}_{2}$ to air $\left(\eta_{\mathrm{tx}}\left(\mathrm{O}_{2}\right.\right.$-air) in Figure 1B; cf. SI for calculation details). Moreover, the $\approx 30 \%$ smaller electrochemical surface area (ECSA) values obtained in PEFC vs. RDE experiments for $\mathrm{Pt}_{3} \mathrm{Ni}$ aerogel (see Table SI-1) imply that the electrode suffers from low utilization, i.e. not all the Pt surface area is available for the electrochemical 
reaction (in contrast to the parity among ECSA values for $\mathrm{Pt} / \mathrm{C}) .{ }^{[3]}$ This condition makes the activity determination less reliable and causes the relatively low surface-specific ORR activity (SA) for $\mathrm{Pt}_{3} \mathrm{Ni}$ in the PEFC which is comparable to the one of $\mathrm{Pt} / \mathrm{C}$ (cf. Figure $1 \mathrm{C}$ and Figure $\mathrm{SI}-2 \mathrm{~B}$ ), ${ }^{[3]}$ whereas from RDE experiments a 3-fold activity enhancement would have been expected (see Figure SI-2A).
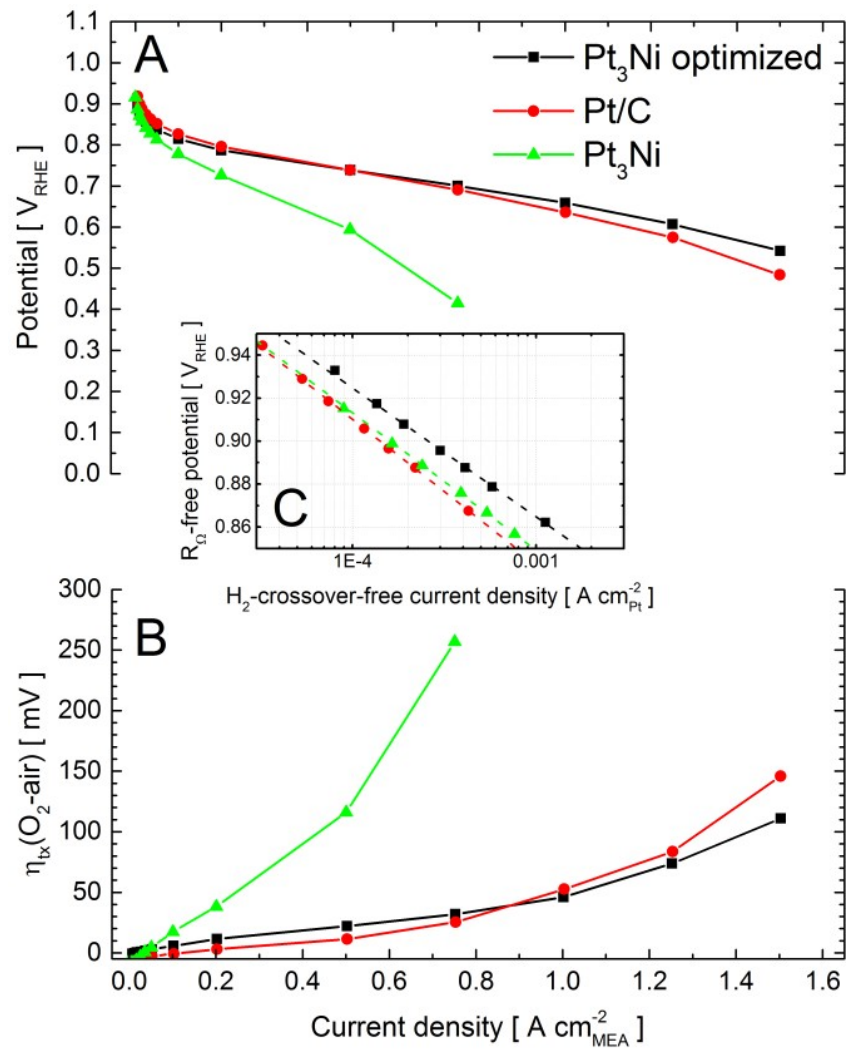

Figure 1. (A) l/E curves at $80^{\circ} \mathrm{C}, 100 \% \mathrm{RH}$ in $\mathrm{H}_{2} /$ air at 1.5 barabs, $_{\text {ab }}$ (B) air vs. $\mathrm{O}_{2}$ mass transfer losses at the cathode (see SI for details) and (C) Tafel plots in $\mathrm{H}_{2} / \mathrm{O}_{2}$ for $\mathrm{Pt}_{3} \mathrm{Ni}$ optimized, $\mathrm{Pt}_{3} \mathrm{Ni}$ and $\mathrm{Pt} / \mathrm{C}$ MEAs $\left(\approx 0.31 \mathrm{mg} \mathrm{Pt} / \mathrm{cm}^{2}\right.$ geom for all cathodes).

To understand the reason for this poor mass transfer, we prepared catalyst layers (CLs) of $\mathrm{Pt}_{3} \mathrm{Ni}$ and $\mathrm{Pt} / \mathrm{C}$ on conductive metal foil substrates (see $\mathrm{SI}$ ) and analyzed their cross section by scanning electron microscopy (SEM). The CL thicknesses for comparable electrode loadings of $\approx 0.5 \mathrm{mgpt} / \mathrm{cm}^{2}$ geom at the

electrode centers amount to $\approx 1.6 \mu \mathrm{m}$ and $\approx 20 \mu \mathrm{m}$ for $\mathrm{Pt}_{3} \mathrm{Ni}$ and
$\mathrm{Pt} / \mathrm{C}$, respectively (see Figures $2 \mathrm{~A}$ and $\mathrm{SI}-3$ ), whereby the latter value is in agreement with the literature. ${ }^{[4 c]}$ Moreover, despite its surface roughness, the average thickness of the $\mathrm{Pt}_{3} \mathrm{Ni} \mathrm{CL}$ is fairly constant along various locations between the electrode's center and edge, as shown in Figure 2C. Additionally, based on the measured thicknesses and assuming densities of $19 \mathrm{~g} / \mathrm{cm}^{3}$ for $\mathrm{Pt}_{3} \mathrm{Ni}$ and $2 \mathrm{~g} / \mathrm{cm}^{3}$ for carbon and ionomer, ${ }^{[3]}$ significantly different porosities of $\approx 64 \%$ for $\mathrm{Pt}_{3} \mathrm{Ni}$ (see Figure SI-4) and $\approx 78 \%$ for $\mathrm{Pt} / \mathrm{C}$ were estimated (disregarding the electrode's edge at $\geq 4.0 \mathrm{~mm}$ from its center).

The impact of the CL structure on the PEFC performance was further clarified by analyzing the corresponding pore size distributions (PSDs) using focused ion beam (FIB) SEM tomography (see Figure SI-5 for representative cross section SEM images). As summarized in Figure 2D, the pores in the $\mathrm{Pt}_{3} \mathrm{Ni} \mathrm{CL}$ are concentrated in the mesoporous range (diameter $<50 \mathrm{~nm}$ ) in which Knudsen diffusion prevails under PEFC operation conditions. ${ }^{[7]}$ This mechanism is considered less efficient than the molecular diffusion in macropores of diameters $>50 \mathrm{~nm}$ and likely explains the poorer mass transport in $\mathrm{Pt}_{3} \mathrm{Ni}$ vs. Pt/C CLs. However, the PSDs and porosities to reach optimal PEFC performance are expected to be different for unsupported $\mathrm{Pt}_{3} \mathrm{Ni}$ aerogel and $\mathrm{Pt} / \mathrm{C}$ CLs due to the dissimilar electrode thickness and catalyst hydrophilicity.

To address the issue of poor mass transport, a filler material was added to the aerogel ink in an attempt to provide a template for pore formation during the initial spray coating step of the catalyst layer onto the membrane (see SI for details). Looking for a salt with high solubility in water that could be easily removed from the resulting catalyst coated membrane (CCM) by a simple washing step, $\mathrm{K}_{2} \mathrm{CO}_{3}$ was selected due to its additional ability to evolve $\mathrm{CO}_{2}$ gas (and potentially further increase the CL's porosity) if the washing step were to be performed in an acidic solution. 

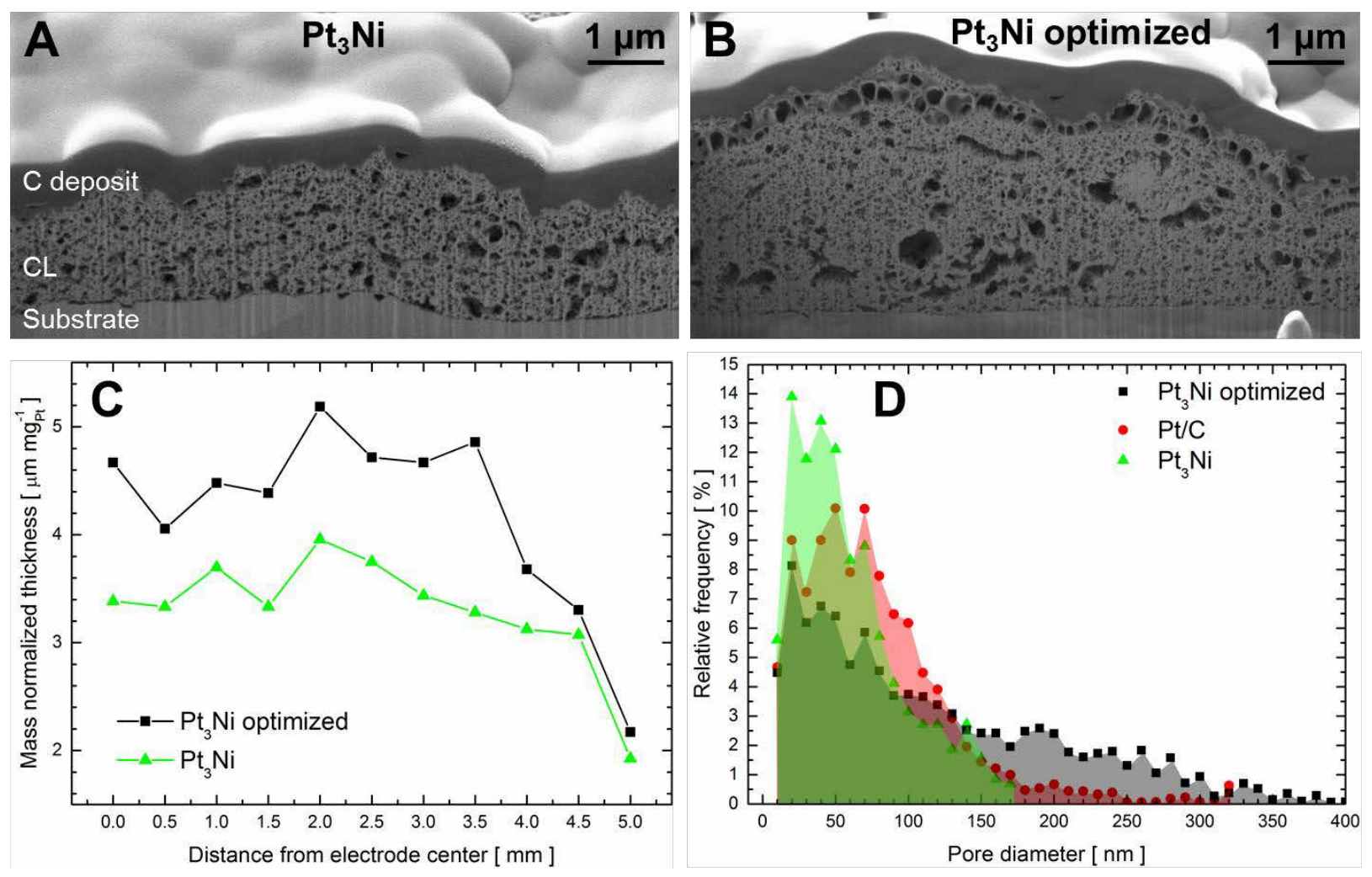

Figure 2. (A, B) Representative cross section SEM images and (C) thickness as a function of the distance from the electrode center for catalyst layers of Pt ${ }_{3} \mathrm{Ni}$ $\left(0.48 \mathrm{mgt}_{\mathrm{Pt}} / \mathrm{cm}^{2}{ }_{\text {geom }}\right)$ and $\mathrm{Pt}_{3} \mathrm{Ni}$ optimized $\left(0.53 \mathrm{mg}_{\mathrm{Pt}} / \mathrm{cm}^{2}\right.$ geom $)$. (D) Pore size distributions derived from FIB SEM tomography for $\mathrm{Pt}_{3} \mathrm{Ni}$, $\mathrm{Pt}_{3} \mathrm{Ni}$ optimized and $\mathrm{Pt} / \mathrm{C} \mathrm{CLs}_{\text {. }}$

Thus, CCMs were prepared according to this approach and the amounts of $\mathrm{K}_{2} \mathrm{CO}_{3}$ and Nafion ionomer ( $\mathrm{Na}^{+}$-exchanged to avoid acidic conditions) were optimized via a series of screening experiments with an abbreviated break-in protocol. First, the volume ratio of salt vs. aerogel and ionomer $\left(\mathrm{V}_{\mathrm{K} 2 \mathrm{CO} 3} / \mathrm{V}_{\mathrm{P}+3 \mathrm{Ni}+\mathrm{Naf}}\right.$, for details see $\mathrm{SI}$ ) was varied between 0 and 1.5 , and subsequently the Nafion-to-catalyst ratio (NCR) was optimized for the best $\mathrm{V}_{\mathrm{K} 2 \mathrm{CO}} / \mathrm{V}_{\mathrm{Pt} 3 \mathrm{Ni}} \mathrm{Naf}$ value.

Figure SI-6A displays the effect of the initial $\mathrm{K}_{2} \mathrm{CO}_{3}$ content on the mass-normalized ORR activities (MAs) at $0.9 \mathrm{~V}_{\mathrm{RHE}}$, which increase by $\approx 90 \%$ before reaching a plateau for $\mathrm{V}_{\mathrm{K} 2 \mathrm{CO}_{3}} / \mathrm{V}_{\mathrm{Pt} 3 \mathrm{Ni}+\mathrm{Naf}}$ values $\geq 0.5$; similarly, the mass of Pt per $\mathrm{kW}$ at $0.65 \mathrm{~V}_{\mathrm{RHE}}$ (in

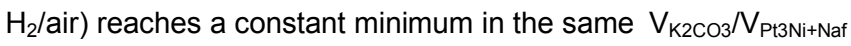

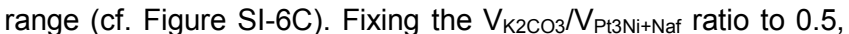
analogous screening experiments (cf. Figure SI-6B/D) yielded an optimized NCR-value of 0.12 .
Such best-performing CLs (referred to as ' $\mathrm{Pt}_{3} \mathrm{Ni}$ optimized' in the following) show greatly improved PEFC performance (Figure 1A) and mass transport properties comparable to those of $\mathrm{Pt} / \mathrm{C}$ electrodes as displayed in Figure 1B, and the CL optimization displays good reproducibility (Figure SI-7). Moreover, the SA of the $\mathrm{Pt}_{3} \mathrm{Ni}$ optimized membrane electrode assembly (MEA) is $\approx 2.5$-fold larger than that of $\mathrm{Pt} / \mathrm{C}$ and $\mathrm{Pt}_{3} \mathrm{Ni}$, as discernable from Figure $1 \mathrm{C}$ and Figure $\mathrm{SI}-2 \mathrm{~B}$, thereby almost matching the $\approx 3$-fold improvement factor observed in RDE experiments (cf. Figure SI-2A). This SA increase coincides with an improved electrode utilization following $\mathrm{CL}$ optimization (from $\approx 75 \%$ to $\approx 95 \%$, cf. Table SI-1), which also becomes apparent when comparing mass-normalized cyclic voltammogramms (CVs) of these two electrodes (see Figure SI-8).

Analysis of $\mathrm{Pt}_{3} \mathrm{Ni}$ optimized CLs by FIB SEM reveals significant increases in thickness (Figure 2B) and porosity (Figure SI-4) 
when compared to $\mathrm{Pt}_{3} \mathrm{Ni} \mathrm{CLs}$, whereby the latter increased from $\approx 64 \%$ to $\approx 74 \%$ and almost matches the value for $\mathrm{Pt} / \mathrm{C}$ $(\approx 78 \%)$. Moreover, the PSDs in Figure $2 \mathrm{D}$ reveal a positive shift in the average pore sizes for $\mathrm{Pt}_{3} \mathrm{Ni}$ optimized vs. $\mathrm{Pt}_{3} \mathrm{NiCLs}$, leading to fewer pores in the mesoporous range and emphasizing the determining role of mesopore vs. macropore diffusion mechanisms on the improved mass transport and

PEFC performance of $\mathrm{Pt}_{3} \mathrm{Ni}$ optimized CLs. ${ }^{[7]}$

To understand how $\mathrm{K}_{2} \mathrm{CO}_{3}$ alters the CL's porosity and PSD,

cross sections of the $\mathrm{P}_{3} \mathrm{Ni}$ optimized $\mathrm{CL}$ before and after acid washing (AW) were studied by SEM and energy dispersive X-ray spectroscopy (EDX) elemental mapping. $\mathrm{Pt}, \mathrm{Ni}$ and $\mathrm{K}$ are homogeneously distributed (cf. Figure SI-9) and there are no indications of large $\mathrm{K}_{2} \mathrm{CO}_{3}$ precipitates. The $\mathrm{K}_{2} \mathrm{CO}_{3}$ is completely dissolved upon acid washing, since the unambiguous potassium Ka-line peak at $\approx 3.3 \mathrm{keV}$ present in the EDX spectra of the as-prepared CL disappeared after AW (cf. Figure SI-10C/D).

Moreover, identical location SEM images recorded before and after AW (cf. Figure SI-10A/B) did not reveal any discernable structural changes of the $C L$ cross section. Together, these observations suggest that $\mathrm{K}_{2} \mathrm{CO}_{3}$ is incorporated in the CLs as precipitates of sizes below $300 \mathrm{~nm}$ (cf. Figure 2D) which dissolve upon AW and thereby shift the CL's porosity and PSD.

Lastly, $\mathrm{Pt}_{3} \mathrm{Ni}$ optimized MEAs were subjected to an AST (10000 cycles between 1.0 and $1.5 \mathrm{~V}_{\mathrm{RHE}}$ at $500 \mathrm{mVs}^{-1}$ ) proposed by the DOE to investigate catalyst support stability. ${ }^{[8]}$ The beginning-

and end-of-life (BOL, EOL) I/E curves in $\mathrm{H}_{2}$ /air in Figure $3 \mathrm{~A}$ illustrate that the performance of the $\mathrm{Pt}_{3} \mathrm{Ni}$ optimized MEAs is sustained throughout the stress test, whereas $\mathrm{Pt} / \mathrm{C}$ suffers from severe degradation. More precisely, the MA at $0.9 \mathrm{~V}_{\mathrm{RHE}}$ decreases by a mere $10 \%$ for $\mathrm{Pt}_{3} \mathrm{Ni}$ optimized, as compared to a $\approx 60 \%$ decrease for $\mathrm{Pt} / \mathrm{C}$, as shown in Figure 3B, highlighting the stability of the $\mathrm{Pt}_{3} \mathrm{Ni}$ aerogel in the investigated potential range.
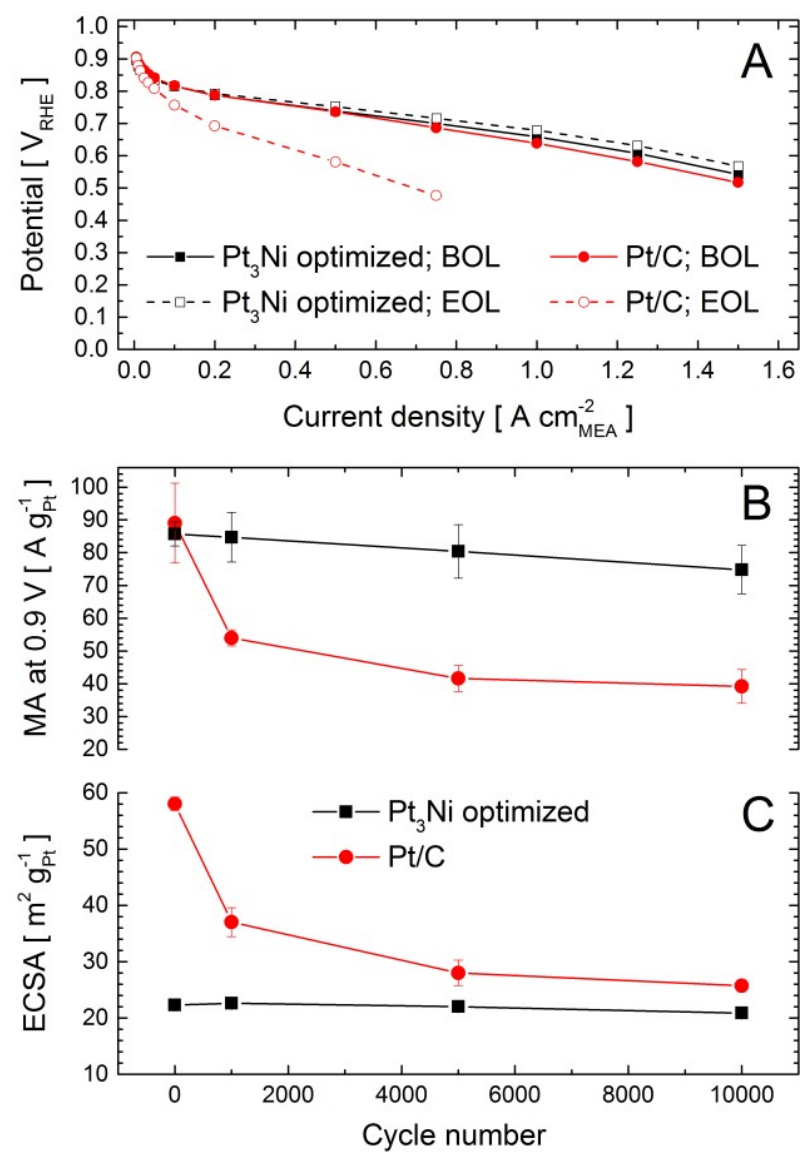

Figure 3. (A) Beginning- and end-of-life $\mathrm{I} / \mathrm{E}$ curves at $80^{\circ} \mathrm{C}, 100 \% \mathrm{RH}$, in $\mathrm{H}_{2}$ /air at 1.5 barabs for the accelerated stress test of $\mathrm{Pt}_{3} \mathrm{Ni}$ optimized and $\mathrm{Pt} / \mathrm{C}$ MEAs (cathode loadings of $0.3-0.4 \mathrm{mg}_{\mathrm{Pt}} / \mathrm{cm}^{2} \mathrm{~m}$ ). (B, C) Average (three repetitions) MA at $0.9 \mathrm{~V}_{\mathrm{RHE}}$ and $\mathrm{ECSA}$ (at $80^{\circ} \mathrm{C}$ ) as a function of the potential cycles between 1.0 and $1.5 \mathrm{~V}_{\mathrm{RHE}}$

Interestingly, the evolution of the ECSA values measured at $80^{\circ} \mathrm{C}$ in Figure $3 \mathrm{C}$ matches that of the mass activities, showing a minor decrease for $\mathrm{Pt}_{3} \mathrm{Ni}$ optimized and $\mathrm{a} \approx 60 \%$ loss for $\mathrm{Pt} / \mathrm{C}$ (see Figure $\mathrm{SI}-11$ for $\mathrm{CVs}$ at different stages of the AST). Consequently, surface-specific activities (cf. Figure SI-12) remain almost constant for $\mathrm{Pt} / \mathrm{C}$ and $\mathrm{Pt}_{3} \mathrm{Ni}$ optimized, indirectly suggesting a lack of change in the catalysts' particle size that should have led to SA changes (on the basis of the well-known particle size effect on SA, cf. references [3, 9]). Thus, mechanisms like Ostwald ripening and particle coalescence that lead to an increase in particle size do not constitute the dominant degradation cause. ${ }^{[10]}$ Instead, in agreement with 
previous literature, ${ }^{[8 a, 10-11]}$ the performance loss for $\mathrm{Pt} / \mathrm{C}$ is mainly attributed to particle detachment due to carbon corrosion.

This additionally leads to a decrease in porosity and average pore size that in terms cause the large EOL mass transport losses in Figure 3A. ${ }^{[12]}$ Albeit minor, the degradation observed for the $\mathrm{Pt}_{3} \mathrm{Ni}$ aerogel is tentatively attributed to metal dissolution, whereby the non-noble $\mathrm{Ni}$ is expected to be leached out of the alloy preferentially. This event can lead to a positive shift of the catalyst's d-band center, thereby decreasing the number of free sites for $\mathrm{O}_{2}$ adsorption and the ORR activity. ${ }^{[13]}$ The details of the degradation mechanism will be studied separately in a

forthcoming work.

In summary, we have for the first time presented the successful implementation of an unsupported aerogel as the ORR catalyst in a PEFC cathode. To achieve the same high current density performance as a $\mathrm{Pt} / \mathrm{C}$ benchmark, $\mathrm{Pt}_{3} \mathrm{Ni}$ aerogel CLs were optimized by adding $\mathrm{K}_{2} \mathrm{CO}_{3}$ to the catalyst ink, which was later removed by acid washing of the CCM. The performance improvement caused by the addition of $\mathrm{K}_{2} \mathrm{CO}_{3}$ is explained by an increase in porosity and average pore size that were calculated from cross section SEM images and FIB SEM tomography data. Additionally, optimized $\mathrm{Pt}_{3} \mathrm{Ni}$ MEAs showed $\mathrm{a} \approx 2.5$-fold increased surface-specific ORR activity with respect to $\mathrm{Pt} / \mathrm{C}$, which is in good agreement with the results from RDE experiments. Finally, the $\mathrm{Pt}_{3} \mathrm{Ni}$ aerogel displayed excellent stability during an AST of 10000 potential cycles between 1.0 and $1.5 \mathrm{~V}_{\mathrm{RHE}}$, making this material a very promising cathode catalyst for PEFCs.

\section{Acknowledgements}

This work was funded by the Swiss National Science Foundation (20001E_151122/1), the German Research Foundation (EY 16/18-1) and the European Research Council (ERC AdG 2013 AEROCAT). The authors thank Dr. Daniel Abbott for the TEM measurement and ScopeM (ETH Zurich) for use of their facilities.

Keywords: Electrochemistry, energy conversion, fuel cells, nanostrustures, alloys

[1] O. Gröger, H. A. Gasteiger, J. P. Suchsland, J. Electrochem. Soc. 2015, 162, A2605-A2622.

[2] W. Liu, P. Rodriguez, L. Borchardt, A. Foelske, J. Yuan, A. K. Herrmann, D. Geiger, Z. Zheng, S. Kaskel, N. Gaponik, R. Kotz, T. J. Schmidt, A. Eychmuller, Angew. Chem. Int. Ed. 2013, 52, 9849-9852.

[3] H. A. Gasteiger, S. S. Kocha, B. Sompalli, F. T. Wagner, Appl. Catal. B: Environ. 2005, 56, 9-35.

[4] a) C. Zhu, D. Du, A. Eychmuller, Y. Lin, Chem. Rev. 2015, 115, 8896-8943; b) T. Tamaki, H. Kuroki, S. Ogura, T. Fuchigami, Y. Kitamoto, T. Yamaguchi, Energy Environ. Sci. 2015, 8, 3545-3549; c) J. Lee, J. M. Yoo, Y. Ye, Y. Mun, S. Lee, O.-H. Kim, H.-W. Rhee, H. I. Lee, Y.-E. Sung, J. Lee, Adv. Energy Mater. 2015, 5, 1402093.

[5] S. Henning, L. Kühn, J. Herranz, J. Durst, T. Binninger, M. Nachtegaal, M. Werheid, W. Liu, M. Adam, S. Kaskel, A. Eychmüller, T. J. Schmidt, J. Electrochem. Soc. 2016, 163, F998-F1003.

[6] I. E. L. Stephens, J. Rossmeisl, I. Chorkendorff, Science 2016, 354, 1378-1379.

[7] a) B. Andreaus, M. Eikerling, in Device and Materials Modeling in PEM Fuel Cells (Eds.: S. J. Paddison, K. S. Promislow), Springer New York, New York, NY, 2009, pp. 41-90; b) N. Nonoyama, S. Okazaki, A. Z. Weber, Y. Ikogi, T. Yoshida, J. Electrochem. Soc. 2011, 158, B416; c) G. A. Schuler, ETH Dissertation 18883 2010, 29 - 32.

[8] a) A. Patru, A. Rabis, S. E. Temmel, R. Kotz, T. J. Schmidt, Catal. Today 2016, 262, 161-169; b) Fuel Cell Technical Team Roadmap, http://energy.gov/sites/prod/files/2014/02/f8/fctt roadmap i une2013.pdf.

[9] a) K. Shinozaki, Y. Morimoto, B. S. Pivovar, S. S. Kocha, Electrochim. Acta 2016, 213, 783-790; b) A. Rabis, P. Rodriguez, T. J. Schmidt, ACS Catal. 2012, 2, 864-890.

[10] J. Speder, A. Zana, I. Spanos, J. J. K. Kirkensgaard, K. Mortensen, M. Hanzlik, M. Arenz, J. Pow. Sourc. 2014, $261,14-22$

[11] a) C. Hartnig, T. J. Schmidt, J. Pow. Sourc. 2011, 196, 5564-5572; b) S. J. Ashton, M. Arenz, J. Pow. Sourc. 2012, 217, 392-399.

[12] H. Schulenburg, B. Schwanitz, N. Linse, G. n. G. Scherer, A. Wokaun, J. Krbanjevic, R. Grothausmann, I. Manke, $J$. Phys. Chem. C 2011, 115, 14236-14243.

[13] V. R. Stamenkovic, B. S. Mun, M. Arenz, K. J. Mayrhofer, C. A. Lucas, G. Wang, P. N. Ross, N. M. Markovic, Nat Mater. 2007, 6, 241 